\title{
Probe-Based Confocal Laser Endomicroscopy Imaging of Endobronchial Hamartomas
}

\author{
Hanaa Shafiek ${ }^{a, e}$ Cristina Gómez $^{b} \quad$ Javier Pierolac Jaume Sauleda ${ }^{\mathrm{a}}{ }^{\mathrm{d}}$ \\ Borja G. Cosío ${ }^{a, d}$ \\ ${ }^{a}$ Department of Respiratory Medicine, ${ }^{b}$ Department of Pathology and ${ }^{\mathrm{C}}$ Research Unit, Hospital Universitario

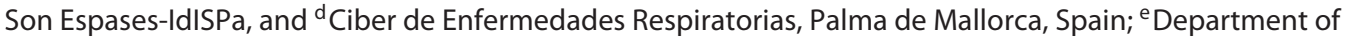 \\ Chest Diseases, Faculty of Medicine, Alexandria University, Alexandria, Egypt
}

\section{Established Facts}

- Hamartomas have a classic histopathological description.

\section{Novel Insights}

- Probe-based confocal laser endomicroscopy demonstrates, for the first time, a real-time in vivo microscopic view of endobronchial hamartoma without the aid of an exogenous dye.

\section{Key Words}

Probe-based confocal laser endomicroscopy •

Endobronchial hamartoma · Bronchoscopy

\section{Abstract}

Probe-based confocal laser endomicroscopy ( $\mathrm{pCLE}$ ) is a new technique that can microscopically image the airways in vivo during ordinary flexible bronchoscope procedures. pCLE can visualize the basement membrane of the bronchial epithelium, allowing the study of the different changes in benign or malignant/premalignant bronchial lesions. We present 2 cas- es of pathology-proven endobronchial hamartoma diagnosed by biopsy which show characteristic images under pCLE examination. The tumor was removed in both cases by rigid bronchoscopy using a diathermy loop and a cryoprobe.

(c) 2014 S. Karger AG, Base

\section{Introduction}

Fibered confocal fluorescence microscopy or probebased confocal laser endomicroscopy (pCLE) is a novel technique capable of providing in vivo microscopic im-

\section{KARGER}

E-Mail karger@karger.com www.karger.com/res
C 2014 S. Karger AG, Basel

0025-7931/14/0886-0484\$39.50/0 

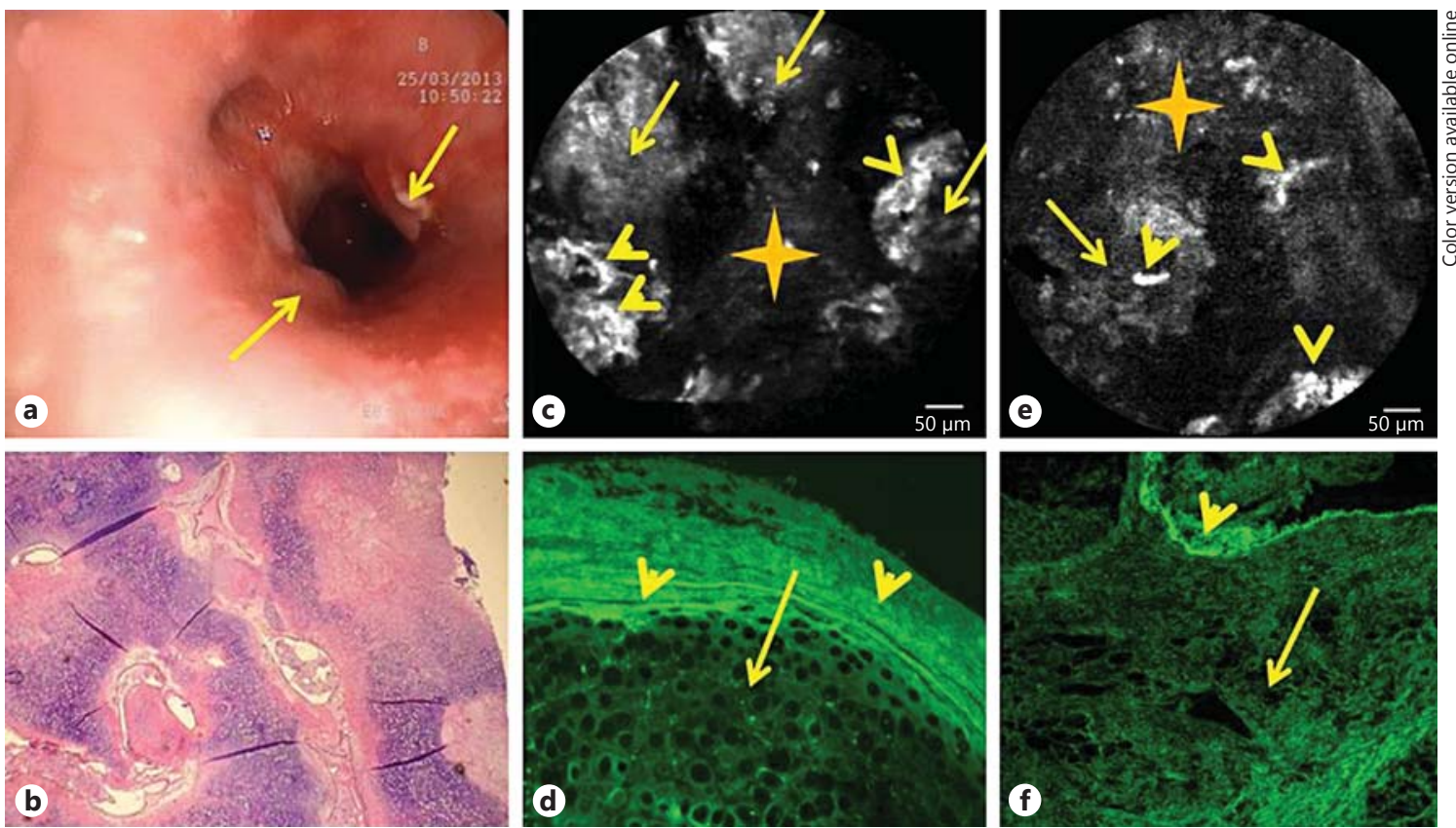

Fig. 1. Bronchoscopic view of the endobronchial hamartoma of case 1 (a), and its pathological examination showing cleft-like spaces between cartilaginous lobules lined by a component of respiratory epithelium, with other differentiated mesenchymal elements (b). HE. pCLE images of both tumors $(\mathbf{c}, \mathbf{e})$ and their fluorescence confocal microscopic images $(\mathbf{d}, \mathbf{f}) \times 10$. The pCLE

ages of both the proximal [1] and distal lung [2]. A very thin and flexible miniprobe (BronchoFlex, Mauna Kea Technologies, Paris, France), containing up to 30,000 compacted microfibers, is advanced through the working channel of the flexible bronchoscope and a fluorescence image is elicited [3]. The pCLE can visualize the elastin component in both the bronchial wall and basement membrane of the bronchial epithelium, which allows the study of the different changes in benign or malignant/premalignant bronchial lesions [1]. We present 2 cases of pathology-proven endobronchial hamartoma which show characteristic images under pCLE examination.

\section{Case Reports}

The first case is a patient with a smoking history of 20 pack-years, initially diagnosed with community-acquired pneumonia in the right lower lobe, who underwent bronchoscopy due to persistent alveolar infiltrate and persistent atelectasis on the control chest X-ray. Bronchoscopy showed a polypoidal mass that caused obstruction of the right laterobasal bronchus and biopsy confirmed the diagnosis of hamartoma where the showed a round heterogeneous aspect (arrows) representing the cartilaginous element (d) and muscular and fatty elements (f), areas of intense autofluorescence (arrowheads) representing the elastic fibers seen in fluorescence confocal microscopy $(\mathbf{d}, \mathbf{f})$ and loss of the normal bronchial wall elastin network (c, e: asterisk).

cartilaginous and fatty elements could mainly be identified (fig. 1b, d).

The second case is a nonsmoker patient with a diagnosis of difficult asthma and suspicion of an endobronchial lesion on a computed tomography scan of the chest, later confirmed by bronchoscopy. A polypoidal mass in the right lower lobe was found and the histological examination confirmed the diagnosis of hamartoma with a predominance of muscular and fatty components (fig. 1f).

In both cases, an examination by pCLE (laser wavelength 488 $\mathrm{nm}$; Cellvizio ${ }^{\circledR}$ LUNG, Mauna Kea Technologies) revealed a similar, characteristic, round heterogeneous aspect representing the tumor component with areas of intense autofluorescence indicating the disrupted elastic fibrin components of the basement membrane and the submucosa covering the tumor (fig. 1). This was clearly seen in the histopathological slides examined ex vivo using fluorescence confocal microscopy (Axio Scope A1, GEP filter ZEISS set 38, excitation BP 470/40, beam splitter FT 495, emission BP 525/50; Carl Zeiss microscopy, Göttingen, Germany). Loss of the normal elastin reticular formation of the proximal bronchial airway was also evident on the pCLE image. This is the first description of a hamartoma using this novel technology. We consider that this could be a valuable tool to help the bronchoscopist to assess endobronchial lesions in real time.

The tumor was removed in both cases by means of rigid bronchoscopy using a diathermy loop and a cryoprobe. Removal of the tumor was associated with complete resolution of the symptoms and this prevented distal lung damage. 


\section{Discussion}

Endobronchial hamartomas are considered to be benign tumors, and they constitute between 8 and $20 \%$ of all lung hamartomas [4-6]. Male predominance has been described $[7,8]$ with a male/female ratio of $6: 1$ and a mean age of $60-70$ years [8]. The majority $(>80 \%)$ of patients with hamartomas are smokers [7]. Hamartomas are frequently asymptomatic, appearing as an incidental radiological or endoscopic finding [7]. However, recurrent respiratory infections or obstructive pneumonia, hemoptysis with or without other respiratory complaints such as cough or dyspnea - leading to misdiagnoses of asthma or chronic obstructive pulmonary disease - have also been reported [8-10]. Computed tomography of the chest can aid in the diagnosis of endobronchial hamartoma either indirectly, by revealing the presence of obstructive pneumonia or atelectasis [11], or directly, by showing an endobronchial lesion with fat density [12, 13]. Histopathological examination is considered the gold standard for proving the diagnosis. The pathological diagnosis depends on the coexistence of different mesenchymal tissues like epithelium, connective tissue, bone, cartilage, muscle and fat $[12,14]$.

In our 2 cases, we used the pCLE for in vivo imaging of the endobronchial lesion. Only a few publications have described benign bronchial pathologies, e.g. bronchial amyloidosis [15] tracheobronchopathia osteochondroplastica [16] and sarcoidosis [1]. To our knowledge, this is the first description of a hamartoma using this novel technology, and we consider that pCLE could prove to be a valuable tool that helps the bronchoscopist to assess endobronchial lesions in real time. Our cases had similar pCLE images that were also highly compatible with the pathological findings. Whereas the round heterogeneous aspect could represent the cartilaginous lobules with other mesenchymal elements demonstrated in the pathological sample, the fluorescent areas inside the tumor could reflect elastic fibrin covering the tumor.

Newton et al. [15] described an homogenous cotton wool appearance for their case of tracheobronchial amyloidosis; our pCLE imaging of hamartomas was more heterogonous. pCLE images of both bronchial sarcoidosis [1] and tracheobronchopathia osteochondroplastica [16] show closed-looking, mottled, autofluorescing submucosa, but do not resemble hamartomas on pCLE. The appearance of hamartoma is different from that of malignant airway lesions described by Thiberville et al. [1], who found $>50 \%$ decrease of fluorescent intensity with specific disorganization of the fibered network in preinvasive malignant lesions. Accordingly, pCLE could provide a helpful new in vivo tool for detecting benign hamartomas and differentiating them from malignant lesions.

\section{References}

-1 Thiberville L, Moreno-Swirc S, Vercauteren T, Peltier E, Cave C, Bourg-Heckly G: In vivo imaging of the bronchial wall microstructure using fibered confocal fluorescence microscopy. Am J Respir Crit Care Med 2007;175: 22-31.

$\checkmark 2$ Thiberville L, Salaun M, Lachkar S, Dominique S, Moreno-Swirc S, Vever- Bizet C, Bourg-Heckly G: Human in-vivo fluorescence microimaging of the alveolar ducts and sacs during bronchoscopy. Eur Respir J 2009; 33:974-985.

-3 Thiberville L, Salaün M, Lachkar S, Dominique S, Moreno-Swirc S, Vever-Bizet C, Bourg-Heckly G: Confocal fluorescence endomicroscopy of the human airways. Proc Am Thorac Soc 2009;6:444-449.

$>4$ Le Roux BT: Pulmonary hamartoma. Thorax 1964;19:236-243.

5 Sibala JL: Endobronchial hamartomas. Chest 1972;62:631-634
-6 Tomashefski JF: Benign endobronchial mesenchymal tumors: their relationship to parenchymal pulmonary hamartomas. Am J Pathol 1982;6:531-540.

7 Gjevre JA, Myers JL, Prakash UB: Pulmonary hamartomas. Mayo Clin Proc 1996;71:14-20.

$>8$ Cosío BG, Villena V, Echave-Sustaeta J, Miguel E, Alfaro J, Hernandez L, Sotelo T: Endobronchial hamartoma. Chest 2002;122: 202-205.

$>9$ Kurkcuoglu IC, Demircan S, Kurul IC, Demirag F: Endobronchial lipomatous hamartoma. Asian Cardiovasc Thorac Ann 2005; 13:372-373.

10 Stey CA, Vogt P, Russi EW: Endobronchial lipomatous hamartoma: a rare cause of bronchial occlusion. Chest 1998;113:254-255.
-11 Altin S, Dalar L, Karasulu L, Çetinkaya E, Timur S, Solmazer N: Resection of giant endobronchial hamartoma by electrocautery and cryotherapy via flexible bronchoscopy. Tuberk Toraks 2007;55:390-394.

12 Stey CA, Vogt P, Russi EW: Endobronchial lipomatous amartoma. A rare cause of bronchial occlusion. Chest 1998;113:254-255.

-13 Ahn JM, Im JG, Seo JW, Han HS, Yoon HK, Kim WS, Yeon KM: Endobronchial hamartoma: CT findings in three patients. AJR 1994; 163:49-50.

14 Borro JM, Moya J, Botella A: Endobronchial hamartoma, report of seven cases. Scand J Thor Cardiovasc Surg 1989;23:285-287.

-15 Newton RC, Kemp SV, Yang GZ, Darzi A, Sheppard MN, Shah PL: Tracheobronchial amyloidosis and confocal endomicroscopy. Respiration 2011;82:209-211.

16 Newton R, Kemp S, Zoumot Z, Yang GZ, Darzi A, Shah PL: An unusual case of haemoptysis. Thorax 2010;65:309,353. 